\title{
Facile Synthesis and Spectral Properties of Aged Gold Colloids
}

\author{
Tang Junqi, Ou Quanhong, Fu Xuewen, Wang Yaqin, Lin Zhiwen, Man Shiqing
}

Yunnan Normal University, Kunming 650500, China

\begin{abstract}
The present paper described the spectra properties of aged gold colloids, which were synthesized by only adding $\mathrm{NaOH}$ to the chloroauric acid and hexadecyl trimethyl ammonium bromide (CTAB) mixture solution. The formation mechanism for the gold nanoparticles (AuNPs) was discussed based on the Fourier transform infrared spectroscopy (FTIR) analysis. The gold colloids with different amounts of $\mathrm{NaOH}$ were aged for three months and then characterized by UV-Vis spectrometer and transmission electron microscopy (TEM). Moreover, surface-enhanced Raman scattering (SERS) spectra of methylene blue (MB) on the three months aged gold colloids were obtained. UV-Vis spectrometer showed the broadening of plasmon absorption peak of three months aged gold colloids. And an explanation for the broadening changes was provided in the as-prepared samples. TEM images demonstrate that the diameter and shape change of the AuNPs depend on addition difference $\mathrm{NaOH}$ at the stage of the synthesis, and the $\mathrm{NaOH}$ also affect the aging process. The corresponding SERS spectra on the aged three months gold colloid display the size/shape-dependent properties. Therefore, we expect that the aged colloidal gold will be developed and applied in biochemical analysis field.
\end{abstract}

Key words: gold nanoparticles; colloids; aging process; surface-enhanced raman scattering (SERS)

Gold nanoparticles (AuNPs) play important roles in many fields. For example, they have been widely exploited for use in surface enhanced Raman scattering (SERS) ${ }^{[1,2]}$, imaging and sensing ${ }^{[3]}$, biological probes ${ }^{[4]}$, photothermal effects $^{[5]}$ and catalysis ${ }^{[6,7]}$. The extensively used procedures to prepare AuNPs in aqueous solutions were reduction of ionic gold by adding a reductant such as sodium citrate, sodium borohydride, ascorbic acid, and tannicacid ${ }^{[8]}$. Recently, synthesis of AuNPs without the use of extra reducing agents or templates have excited great interest among materials and chemical researchers. Zhou and co-workers $^{[9]}$ reported the synthesis of extremely stable size-controlled AuNPs in the presence of polyvinylpyrrolidone (PVP) without the use of extra reducing agent. Huang and co-workers ${ }^{[10]}$ described a surfactant-promoted reductive route for the shape-controlled synthesis of gold nanostructures by hydrothermal treatment of chloroauric acid in the presence of the surfactant CTAB without using extra reducing agent. Since CTAB molecules promoted reduction of $\mathrm{Au}^{\mathrm{III}}$ to $\mathrm{Au}^{0}$ involving in these researches need strict conditions, we can develop a simpler and more facile method to AuNPs synthesis and its scope of application could be further expanded by studying the optical properties.

Our group has published a paper on preparation and characterization of AuNPs without extra reducing agent by adding different amounts of $\mathrm{NaOH}$ to $\mathrm{CTAB}$ and $\mathrm{HAuCl}_{4}$ mixture solution at room temperature ${ }^{[11]}$. Consequently, here we would like to study the spectra properties of aged gold colloids. The various spectra of colloidal solution were determined after aging for a period of three months. In addition, the aged gold colloids with adding different amounts of $\mathrm{NaOH}$ have been applied in SERS analysis with methylene blue (MB) as a probe molecule. The SERS

Received date: February 02, 2016

Foundation item: National Natural Science Foundation of China (21171072, 21361028); Yunnan Applied Basic Research Projects (2014FB140); Scientific Research Foundation for Ph. D.'s of Yunnan Normal University

Corresponding author: Man Shiqing, Ph. D., Professor, College of Physics and Electronic Information, Yunnan Normal University, Kunming 650500, P. R. China, Tel: 0086-871-65941177, E-mail: man_shiqing@yahoo.com 
spectra of $\mathrm{MB}$ acquired and indicated that enhancement effect of Au colloids has relation with size and shape. The aged colloidal gold could be explored and applied in the biochemical analysis field.

\section{Experiment}

Chloroauric acid $\left(\mathrm{HAuCl}_{4} \cdot 4 \mathrm{H}_{2} \mathrm{O}, \mathrm{Au}>47.8 \%\right)$ was obtained from Shanghai Chemical Reagent Co., Ltd. Cetyl trimethyl ammonium bromide (CTAB, 99\%) was supplied by Tianjin Kemiou Chemical Reagent Co. Ltd. Sodium hydroxide $(\mathrm{NaOH}, 96 \%)$ was purchased from Guangzhou Chemical Reagent Factory. All chemicals were of analytical reagent grade and used without further purification. 18.2 $\mathrm{M} \Omega \cdot \mathrm{cm}$ E-pure water was used throughout the experiments. Then colloids were prepared according to the reported procedure $^{[11]}$. Briefly, an amount of $\mathrm{NaOH}(1 \mathrm{~mol} / \mathrm{L})$ was added to $10 \mathrm{~mL}$ of $\mathrm{CTAB}$ and $\mathrm{HAuCl}_{4}$ mixture solution with vigorous stirring. The mixed solution was continuously stirred for $24 \mathrm{~h}$ until the formation of light red solution. The morphologies and sizes of nanoparticles varied with changing the addition of the $\mathrm{NaOH}$ solution in the reaction system. All colloidal solutions were covered away from light and aged for three months at room temperature. Next, the AuNPs were collected for spectra analysis and characterization.

FT-IR spectra were recorded at room temperature using a Bruker Equinox 55 spectrometer equipped with a DTGS detector, operating in the spectral range $400 \sim 2000 \mathrm{~cm}^{-1}$ with a resolution of $4 \mathrm{~cm}^{-1}$. The UV-Vis spectra of aged colloid solution were recorded using a UV-Vis spectrophotometer (SHIMADZU UV-2550) in a $1 \mathrm{~cm}$ optical path quartz cuvette. The size distribution and morphology of the nanoparticles were examined by TEM. TEM observations were carried out on a PHILIPS TECNAL-10 electron microscope operating at $100 \mathrm{kV}$. Raman spectra were recorded between 200 and $2000 \mathrm{~cm}^{-1}$ and used a $785 \mathrm{~nm} \mathrm{(40}$ $\mathrm{mW}$ ) excitation Raman spectrometer (Advantage Raman Series, DeltaNu). Normal Raman measurements of $0.1 \mathrm{~mol} / \mathrm{L}$ MB solution were carried out at room temperature and the accumulation time were $20 \mathrm{~s}$. For SERS measurements, the sample was prepared by adding $10 \mu \mathrm{L}$ of $50 \mathrm{mmol} / \mathrm{L}$ aqueous solution of $\mathrm{MB}$ to $1 \mathrm{~mL}$ aged gold colloid into a 1 $\mathrm{mL}$ glass cuvette. The measurements were started after $\mathrm{MB}$ and colloids were mixed uniformly in ambient environment with integration time of $5 \mathrm{~s}$.

\section{Results and Discussion}

\subsection{Formation of AuNPs}

AuNPs were synthesized by a two-step procedure. The first step involves the reaction between $\mathrm{OH}^{-}$and $\mathrm{AuCl}_{4}{ }^{-}, \mathrm{Br}^{-}$ and $\mathrm{AuCl}_{4}{ }^{-}$, and the second step involves the reduction of $\mathrm{Au}^{\text {III }}$ using CTAB molecular. Firstly, the chloroauric acid anion $\left(\left[\mathrm{AuCl}_{4}\right]^{-}\right)$undergoes the hydrolysis reaction in water to form six major species of the general form $\left[\mathrm{AuCl}_{4-x}(\mathrm{OH})_{x}\right]^{-} \quad(x=0 \sim 4)^{[12,13]}$. While the gold-halide complexes anions of the form $\left[\mathrm{AuX}_{4}\right]^{-}(X=\mathrm{F}, \mathrm{Cl}, \mathrm{Br}, \mathrm{I})$ with a decreased stability of the series $(\mathrm{I}>\mathrm{Br}>\mathrm{Cl}>>\mathrm{F})^{[14]}$. The exchange of $\mathrm{Cl}^{-}$in $\left[\mathrm{AuCl}_{4-\mathrm{x}}(\mathrm{OH})_{x}\right]^{-}(x=0 \sim 4)$ with $\mathrm{Br}^{-}$takes place simultaneously. So $\left[\mathrm{AuBr}_{4-x}(\mathrm{OH})_{x}\right]^{-}$and $\left[\mathrm{AuCl}_{4-x^{-}}\right.$ $\left.(\mathrm{OH})_{x}\right]^{-}$coexist in the $\mathrm{HAuCl}_{4}$ and $\mathrm{CTAB}$ mixed aqueous solution (Eqs. 1 and 2) ${ }^{[11]}$. However, it is well-known that surfactant molecules self-assemble into aggregates in aqueous solution above the so-called critical micelle concentration (CMC). In this study, the CTAB concentration was $5 \mathrm{mmol} / \mathrm{L}$, and the aggregates were generally spherical-like micelles ${ }^{[15,16]}$. Adding a certain amount of $\mathrm{NaOH}$ solution, the counterion $\mathrm{Br}^{-}$in $\mathrm{CTAB}$ is replaced by nucleophilic $\mathrm{OH}^{-}$and $\mathrm{CTAB}$ was thus transformed to cetyl trimethyl ammonium hydroxide $(\mathrm{CTAOH})$ in second step (Eq.3) ${ }^{[17,18]} \cdot\left[\mathrm{AuBr}_{2}(\mathrm{OH})_{2}\right]^{-}$, $\left[\mathrm{AuBr}(\mathrm{OH})_{3}\right]^{-}$, even $\left[\mathrm{Au}(\mathrm{OH})_{4}\right]^{-}$will dominate in the solution for higher $\mathrm{pH}$ value. And then the ligands of $\mathrm{OH}^{-}$in $\mathrm{CTAOH}$ and $\mathrm{OH}^{-}$ligands in $\left[\mathrm{AuBr}_{4-x}(\mathrm{OH})_{x}\right]^{-}$are bonded together in spherical-like micelles. The Au-O-CTA (substitute) complexes are formed by the dehydration reaction (Eq. 4), just like the growth unit model of oxide crystals proposed by Zhong et al. ${ }^{[19,20]}$. After this initial nucleation, the complexes function as seeds and increase with time until the formation of AuNPs. The entire process is in accordance with the nucleation-growth pathway ${ }^{[21]}$. Then, the colloidal gold solution was stood up for the stage of aging.

The CTA (substitute)-capped AuNPs was analyzed firstly by FTIR measurements. It can be seen from Fig. 1 that the rocking mode of the methylene chain $\left(\left(\mathrm{CH}_{2}\right)_{n}, n>4\right)$ is detected at $725 \mathrm{~cm}^{-1}$, the $\mathrm{C}-\mathrm{N}^{+}$stretching bands are found at 910 and $962 \mathrm{~cm}^{-1}$, the asymmetric and symmetric $\mathrm{C}-\mathrm{H}$ scissoring vibrations of $\mathrm{CH}_{3}-\mathrm{N}^{+}$moiety is observed at 1405 and $1465 \mathrm{~cm}^{-1}$, and the $\mathrm{H}-\mathrm{O}-\mathrm{H}$ bend mode is detected at $1639 \mathrm{~cm}^{-1[11,18,22]}$. Those peaks are observed at both pure CTAB and CTA-capped AuNPs. The new bands of CTA-capped AuNPs at 603 and $848 \mathrm{~cm}^{-1}$ are considered as $\mathrm{Au}-\mathrm{O}$ and $\mathrm{N}-\mathrm{O}$ stretching vibrations ${ }^{[23]}$, the protons at $\alpha-\mathrm{CH}_{2}$ and $\beta-\mathrm{CH}_{2}$ methylene of CTA radical could be affected by the near-field effect or surface effect of AuNPs for the interaction of hydrophilic headgroups of CTAB molecules and AuNPs surface. The results are significantly different from the previous report ${ }^{[11]}$. But these analyses are more sufficient to convince the reaction of CTA-capped AuNPs synthesis than the previous ones. All of the reaction equations for the formation of AuNPs are as follows.

$$
\begin{aligned}
& \mathrm{AuCl}_{4}^{-}+x \mathrm{OH}^{-} \rightarrow\left[\mathrm{AuCl}_{4-x}(\mathrm{OH})_{x}\right]^{-}+x \mathrm{Cl}^{-} \\
& {\left[\mathrm{AuCl}_{4-x}(\mathrm{OH})_{x}\right]^{-}+(4-x) \mathrm{Br}^{-} \rightarrow\left[\mathrm{AuBr}_{4-x}(\mathrm{OH})_{x}\right]^{-}+} \\
& (4-x) \mathrm{Cl}^{-}
\end{aligned}
$$




$$
\begin{aligned}
& \mathrm{CTA}^{+} \mathrm{Br}^{-}+\mathrm{Na}^{+} \mathrm{OH}^{-} \rightarrow \mathrm{CTA}^{+} \mathrm{OH}^{-}+\mathrm{Na}^{+} \mathrm{Br}^{-} \\
& {\left[\mathrm{AuBr}_{4 \cdot x} \mathrm{OH}_{x}\right]^{-}+\mathrm{CTA}^{+} \mathrm{OH}^{-} \rightarrow} \\
& \mathrm{Au}^{-} \mathrm{O}^{-} \mathrm{CTA} \text { (substitude) }+(4-x) \mathrm{Br}^{-}+x \mathrm{H}_{2} \mathrm{O}
\end{aligned}
$$

\subsection{Analysis of UV-Vis spectroscopy}

A slight precipitate phenomenon is noticed during the colloidal aging. After three months aging, no further sedimentation of the colloids could be observed with naked eyes, which implies the colloidal solutions reach a relatively stable state. Before analysis of spectral performance, the solutions were shaken evenly. Then, the aged gold colloid was characterized by UV-Vis spectrometer at room temperature. UV-Vis spectra (Fig.2) show gold colloids obtained by $[\mathrm{CTAB}]=5 \mathrm{mmol} / \mathrm{L}$ and $\left[\mathrm{HAuCl}_{4}\right]=0.25 \mathrm{mmol} / \mathrm{L}$ with adding $600 \mu \mathrm{L}$ of $1 \mathrm{~mol} / \mathrm{L}$ $\mathrm{NaOH}$, in $10 \mathrm{~h}, 24 \mathrm{~h}$ and three-month aged state. The colloids prepared after 10 and $24 \mathrm{~h}$ have the same surface plasma resonance (SPR) peaks at $522 \mathrm{~nm}$ (Fig.2). The Full width at half maximum (FWHM) of absorption lines is very similar to 64.5 and $69.5 \mathrm{~nm}$. The two spectra of samples have an almost identical shape, representing the synthesis reaction is almost completed in about $10 \mathrm{~h}$. The maximum absorption peak position shifts from $522 \mathrm{~nm}$ to $529 \mathrm{~nm}$ after three-month aging, while the FWHM changes noticeably and is broadened to $159 \mathrm{~nm}$ with the aged process. Indeed, it is well established that the bandwidth is inversely proportional to the diameter of the gold nanoparticle in the intrinsic size region (mean diameter smaller than $25 \mathrm{~nm}$ ), indicating smaller size particles in aged colloid ${ }^{[24]}$. This phenomenon is related to the size-dependent surface plasmon absorption in metal nanoparticles, which has been studied in detail by El-Sayed et al. ${ }^{[24,25]}$, and also confirmed in the subsequent results of TEM observations in this study.

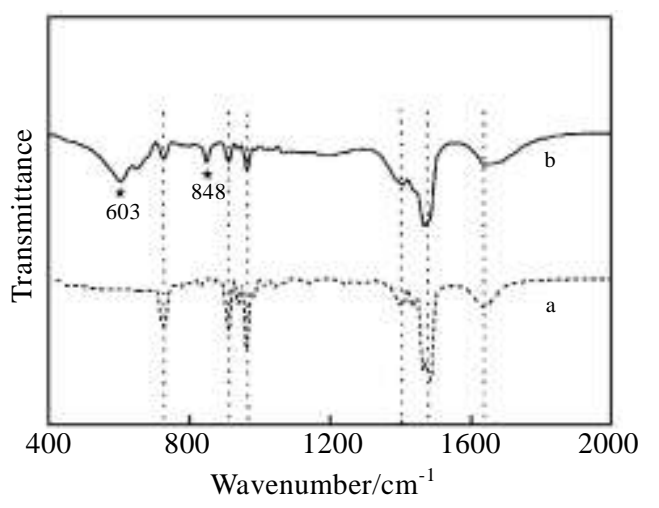

Fig.1 FTIR spectra of pure CTAB (a) and the nanoparticles capped by CTA-substitute (b)
Fig.3 and Fig. 4 show UV-Vis absorption spectra of gold colloids prepared by adding 150 and $25 \mu \mathrm{L}$ of $1 \mathrm{~mol} / \mathrm{L} \mathrm{NaOH}$ to the CTAB and $\mathrm{HAuCl}_{4}$ mixture solution, respectively. The plasmon absorption of all prepared colloids is clearly visible. The FWHM of the aged colloid by adding $150 \mu \mathrm{L}$ of $\mathrm{NaOH}$ is also larger than that of colloid prepared after 10 and $24 \mathrm{~h}$, which increases from $55 \mathrm{~nm}$ to $98 \mathrm{~nm}$. And the maxima of the plasmon absorption for $10 \mathrm{~h}$ and $24 \mathrm{~h}$ synthesized colloidal solutions are observed at $522 \mathrm{~nm}$, and gradually shift and increase to $535 \mathrm{~nm}$ for the aged sample (Fig.3). The broadening bandwidth implies that the diameter of AuNPs is also gradually decreased in the aging process, because the bandwidth is strongly size-dependent and inversely proportional to the diameter $R$ of particles within the range of intrinsic size effects, approximately below $R=25 \mathrm{~nm}$ for $\mathrm{Ag}$ or $\mathrm{Au}^{[24,26,27]}$. Therefore, we can observe the broadening of adsorption peak in the aging gold colloids. These colloids are expected to obtain smaller particles, and the results are confirmed by the followed TEM images.

However, the AuNPs samples synthesized by adding $25 \mu \mathrm{L}$ of $\mathrm{NaOH}$ show an entirely different aging process. In the UV-Vis spectra of the colloids a blue-shift occurs within the first $24 \mathrm{~h}$, followed by a red shift in the period of aging. The peak position changes from $529.5 \mathrm{~nm}$ at $10 \mathrm{~h}$ to $526 \mathrm{~nm}$ at 24 $\mathrm{h}$, and the position of aged colloid is located at $537.5 \mathrm{~nm}$ (Fig.4). It is suggested that the synthesis of nanoparticles is a slow process with adding small amounts of $\mathrm{NaOH}$. The large particles (or aggregations) are formed at the first stage and decompose into small particles at the sequence stage. At the aging stage, the small particles grow slightly through the ripening process. The SPR bandwidth of gold nanoparticles increases from $88 \mathrm{~nm}$ to $121 \mathrm{~nm}$. Besides, both aged colloids in Fig. 3 and Fig.4 exhibit increase of absorption peak intensity, which means the increase of nanoparticle

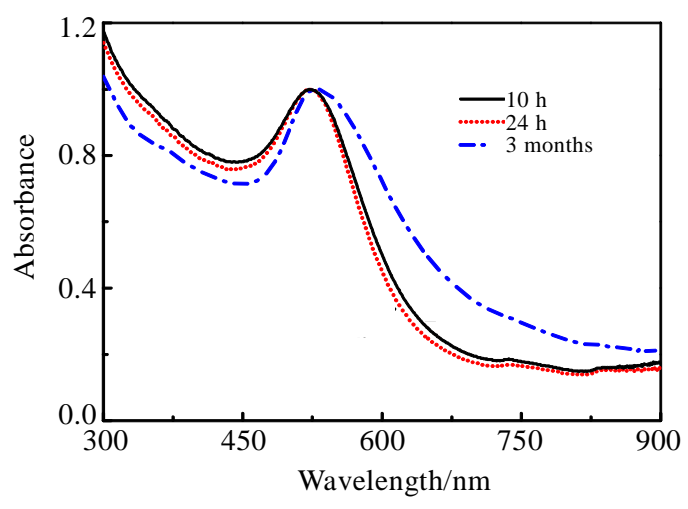

Fig.2 Normalized UV-Vis spectra of gold colloids obtained by $[\mathrm{CTAB}]=5 \mathrm{mmol} / \mathrm{L}$ and $\left[\mathrm{HAuCl}_{4}\right]=0.25 \mathrm{mmol} / \mathrm{L}$ with adding $600 \mu \mathrm{L}$ of $1 \mathrm{~mol} / \mathrm{L} \mathrm{NaOH}$, in $10 \mathrm{~h}, 24 \mathrm{~h}$ and three-month aged state 


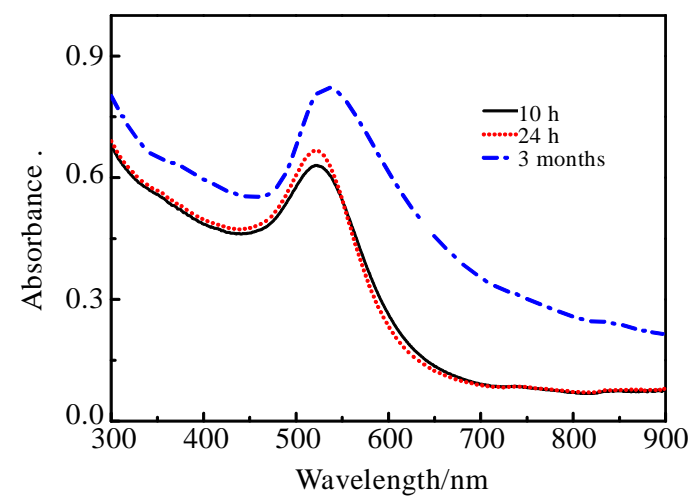

Fig.3 UV-Vis spectra of gold colloids obtained by $[\mathrm{CTAB}]=5$ $\mathrm{mmol} / \mathrm{L}$ and $\left[\mathrm{HAuCl}_{4}\right]=0.25 \mathrm{mmol} / \mathrm{L}$ with adding $150 \mu \mathrm{L}$ of $1 \mathrm{~mol} / \mathrm{L} \mathrm{NaOH}$, in $10 \mathrm{~h}, 24 \mathrm{~h}$ and three-month aged state

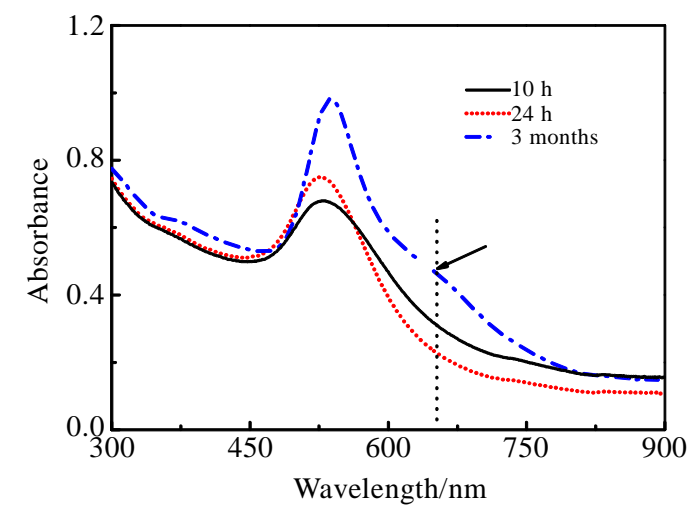

Fig.4 UV-Vis spectra of gold colloids obtained by [CTAB]= $5 \mathrm{~m} \mathrm{~mol} / \mathrm{L}$ and $\left[\mathrm{HAuCl}_{4}\right]=0.25 \mathrm{mmol} / \mathrm{L}$ with adding $25 \mu \mathrm{L}$ of $1 \mathrm{~mol} / \mathrm{L} \mathrm{NaOH}$, in $10 \mathrm{~h}, 24 \mathrm{~h}$ and three-month aged state

concentration $^{[28]}$. Meanwhile, a shoulder peak (marked by a dark arrow) at $650 \mathrm{~nm}$ is observed. This absorption spectrum indicated the presence of non-spherical nanoparticles in the aged colloidal solution. It may be explained by the TEM image of the aged sample.

\subsection{TEM analysis}

Fig.5 shows TEM images of three-month aged gold colloids and the inserted images are the fresh gold colloids. The fresh prepared AuNPs was discussed in detail in our previous report ${ }^{[11]}$. As for the aged AuNPs, the diameter of the aged AuNPs prepared by adding 600 and $150 \mu \mathrm{L}$ of $\mathrm{NaOH}$ is smaller than that of colloid prepared after $24 \mathrm{~h}$ (Fig.5a and 5b). As suggested above, the change of particle size leads to the broadening of

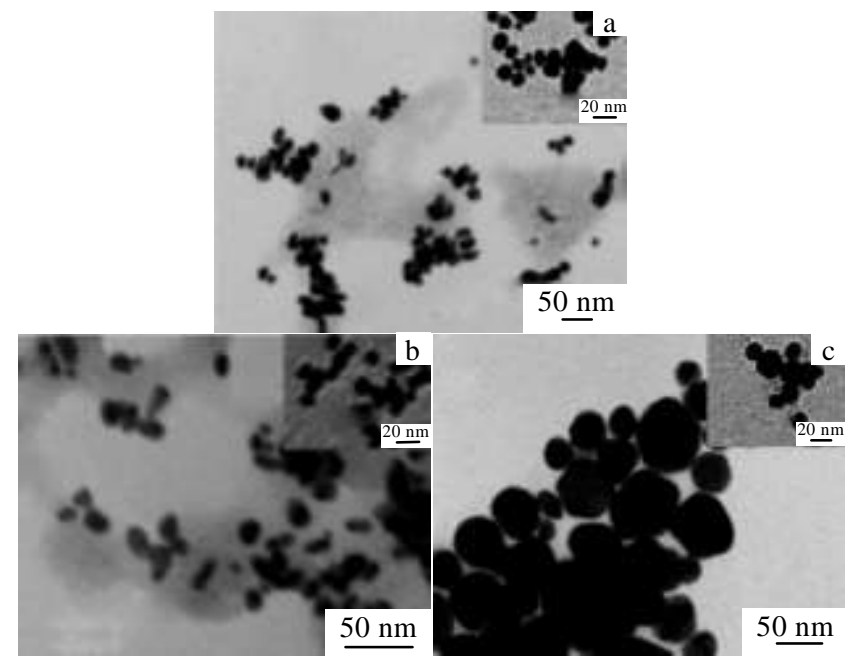

Fig.5 TEM images of aged gold nanoparticles colloids prepared with different amounts of $\mathrm{NaOH}$ the inserted are the fresh particles images: (a) $600 \mu \mathrm{L}$, (b) $150 \mu \mathrm{L}$, (c) $25 \mu \mathrm{L}$

plasmon absorption peak. The microscopic mechanisms of colloid aging cause smaller nanoparticles we can consult the earlier report about fabricating nanoparticles by a selective sedimentation of the colloids ${ }^{[27]}$. Fig. 5c presents the size distribution of aged gold colloid by adding $25 \mu \mathrm{L}$ of $\mathrm{NaOH}$. This aged colloid contains more irregular particles and the diameter of AuNPs is increased to around $50 \mathrm{~nm}$ (a few over $60 \mathrm{~nm}$ ). It is well known that the diameters of gold or silver nanoparticle are over $25 \mathrm{~nm}$ (extrinsic region), and the SPR bandwidth increases with increase in particle size ${ }^{[29]}$. The result suggests that the large anisotropy nanoparticles gradually form during the aging process. In general, coarsening is governed by the growth of larger particles at the expense of smaller particles in the solution-phase synthesis ${ }^{[30]}$. Hence, the growth of larger AuNPs is based on this ripening process and promotes the formation of faceted nanoparticles. These nanoparticles may be capable of causing surface enhancement of Raman signals and be used to SERS-active probe.

\subsection{SERS activity}

To investigate the SERS sensitivity of these aged colloids, the SERS spectra of MB were measured. For comparison, the normal Raman spectrum of $0.1 \mathrm{~mol} / \mathrm{L} \mathrm{MB}$ was also presented. Curves a, b and c in Fig.6 represent the surface-enhanced Raman spectra of aged colloids synthesized by adding 600, 150 and $25 \mu \mathrm{L}$ of $\mathrm{NaOH}$, respectively. All of the spectra exhibit similar shape, 


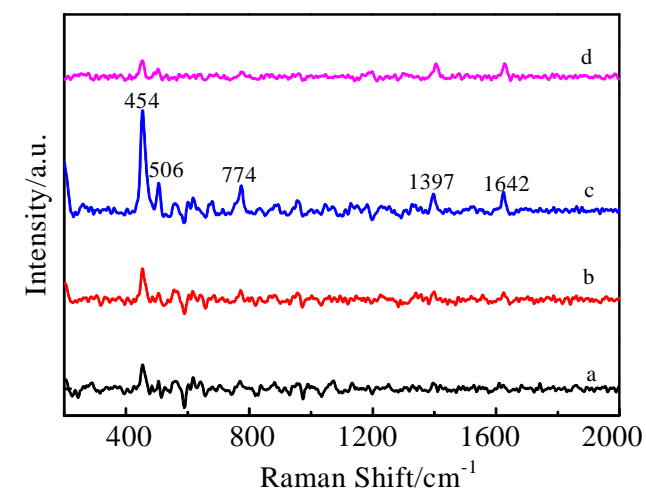

Fig.6 SERS spectra (integration time: $5 \mathrm{~s}$ ) of MB molecules absorbed on AuNPs with adding different amounts of NaOH: (a) $600 \mu \mathrm{L}$, (b) $150 \mu \mathrm{L}$, (c) $25 \mu \mathrm{L}$, and (d) Normal Raman spectrum (NRS) of $0.1 \mathrm{~mol} / \mathrm{L}$ of $\mathrm{MB}$ solution (integration time: $20 \mathrm{~s}$ )

while the enhanced signal intensities are distinguished from each other. It is well known that SERS effect occurs because of the very strong electromagnetic fields and field gradients available in the so-called "hot spots" of the colloidal nanoparticle cluster ${ }^{[31]}$. Hot spots are so important to SERS enhancement performance which are affected by the size, shape, composition, spacing and surface active-site of the nanoparticles. Simultaneously, the SERS signal intensities are proportional to the Raman cross section of the adsorbed molecule, the excitation laser intensity, and the number of molecules. In this paper, the size and shape of nanoparticles are the two major aspects to be considered. Fig. 5 shows that the anisotropic and larger nanoparticles are synthesized by adding a fewer amount of $\mathrm{NaOH}$. And it can be seen in Fig. 5c that the maximum diameter of the nanoparticles is about $64 \mathrm{~nm}$. According to previous reports, the irregular metal nanoparticles can induce stronger SERS enhancement, and $60 \mathrm{~nm}$ colloidal $\mathrm{Au}$ particles can obtain the most intense SERS spectra signal in the size range of $20 \sim 100 \mathrm{~nm}^{[32,33]}$. Hence, the aged gold colloid by adding 25 $\mu \mathrm{L}$ of $\mathrm{NaOH}$ achieves the largest enhancement effect. These frequencies and intensities of SERS bands are different from that of the normal Raman (curve d in Fig.6). And all the observed peaks are assigned. In normal Raman the most intense bands are observed at 453, 1405 and $1628 \mathrm{~cm}^{-1}$ due to C-S-C skeletal bending, C-N stretching and C-C stretching band, respectively. In SERS, the intense bands are obviously observed at 454, 506, 774, 1397 and 1621 $\mathrm{cm}^{-1}$. The bands at 506 and $774 \mathrm{~cm}^{-1}$ are assigned to $\mathrm{C}-\mathrm{N}-\mathrm{C}$ skeletal bending and $\mathrm{C}-\mathrm{H}$ out-of-plane bending, respectively. The C-S-C skeletal bending, C-N stretching and C-C stretching band are shifted to 454, 1397 and 1621 $\mathrm{cm}^{-1}$, respectively ${ }^{[34,35]}$. According to the "surface selection rules" for the interpretation of SERS data on the orientation of adsorbed molecule relation to the metal surface ${ }^{[36]}$, it is estimated that MB molecules adopt a parallel orientation on the gold nanoparticles surface. From this viewpoint, the relative intensities of bands at 454 and $506 \mathrm{~cm}^{-1}$ of all spectra are the largest.

\section{Conclusions}

1) Aged gold colloids are synthesized by alkaline $\mathrm{HAuCl}_{4}$ and CTAB mixture solution.

2) Adding a small quantity of $\mathrm{NaOH}$ promotes the formation of irregular nanoparticles during the aging process. All the aged gold colloids show broadening of plasmon absorption peaks in UV-Vis spectra.

3) Additionally, the irregular nanoparticles of the aged colloid present enormous SERS activity and should be an ideal system for application in SERS probe and sensor.

\section{References}

1 Zhang D F, Zhang Q, Niu L Y et al. Journal of Nanoparticle Research[J], 2011, 13(9): 3923

2 Gan Q, Zhang G N, Su Y et al. Chinese Journal of Analytical Chemistr[J], 2015, 42(7): 1022 (in Chinese)

3 Huang C F, Yao G H, Liang R P et al. Biosensors \& Bioelectronics [J], 2013, 50: 305

4 Culha M. Appl Spectrosc[J], 2013, 67(4): 355

5 Llorca J, Casanovas A, Dominguez M et al. Journal of Nanoparticle Research[J], 2008, 10(3): 537

6 Dong Y N, Dong S A, Tang C et al. Rare Metal Materials and Engineering [J], 2013, 42(4): 789 (in Chinese)

7 Lin Y, Li Z, Chen Z et al. Biomaterials[J], 2013, 34(11): 2600

8 Daniel M C, Astruc D. Chemical Reviews[J], 2004, 104(1): 293

9 Zhou M, Wang B, Rozynek Z et al. Nanotechnology[J], 2009, 20: 505606

10 Huang Y Z, Wang W Z, Liang H Y et al. Crystal Growth \& Design[J], 2009, 9(2): 858

11 Tang J, Huang J, Man S Q. Spectrochimica Acta Part A: Molecular and Biomolecular Spectroscopy[J], 2013, 103(1): 349

12 Kah J C Y, Phonthammachai N, Wan R C Y et al. Gold Bulletin[J], 2008, 41(1): 23

13 Wang S, Qian K, Bi X Z et al. The Journal of Physical Chemistry $C[\mathrm{~J}], 2009,113(16): 6505$

14 Usher A, McPhail D, Brugger J. Geochimica et Cosmochimica Acta[J], 2009, 73(11): 3359

15 Lin Z, Cai J, Scriven L et al. The Journal of Physical Chemistry[J], 1994, 98(23): 5984

16 Lu H J, Chen C, Guo H T et al. Acta Chimica Sinica[J], 2006, 
64(24): 2437 (in Chinese)

17 Balakrishnan V K, Han X M, Vanloon G W et al. Langmuir [J], 2004, 20(16): 6586

18 Sui Z, Chen X, Wang L et al. Physica E: Low-dimensional Systems and Nanostructures[J], 2006, 33(2): 308

19 Zhong W Z, Liu G Z, Shi E W et al. Science China Chemistry[J], 1994, 4: 002 (in Chinese)

20 Li W J, Shi E W, Zhong W Z et al. Journal of Crystal Growth[J], 1999, 203(1-2): 186

21 Ji X, Song X, Li J et al. Journal of the American Chemical Society[J], 2007, 129(45): 13939

22 Nikoobakht B, El-Sayed M A. Langmuir[J], 2001, 17(20): 6368

23 Ferraro J R. Low-frequency Vibrations of Inorganic and Coordination Compounds[M]. Berlin: Springer Science \& Business Media, 2012

24 Link S, El-Sayed M A. The Journal of Physical Chemistry $B[\mathrm{~J}], 1999,103(40): 8410$

25 Link S, El-Sayed M A The Journal of Physical Chemistry $B[\mathrm{~J}]$, 1999, 103(21): 4212

26 Pinchuk A, Kreibig U, Hilger A. Surface Science[J], 2004, 557(1): 269
27 Zhu X P, Suzuki T, Nakayama T et al. Chemical Physics Letters[J], 2006, 427(1-3): 127

28 Baladi A, Mamoory R S. Applied Surface Science[J], 2010, 256(24): 7559

29 Philip D. Spectrochimica Acta Part a-Molecular and Biomolecular Spectroscopy[J], 2008, 71(1): 80

30 Penn R L, Oskam G, Strathmann T J et al. The Journal of Physical Chemistry B[J], 2001, 105(11): 2177

31 Leopold N, Lendl B. The Journal of Physical Chemistry B[J], 2003, 107(24): 5723

32 Krug J T, Wang G D, Emory S R et al. Journal of the American Chemical Society[J], 1999, 121(39): 9208

33 Emory S R, Haskins W E, Nie S. Journal of the American Chemical Society[J], 1998, 120(31): 8009

34 Xiao G N, Man S Q. Chemical Physics Letters[J], 2007, 447(4-6): 305

35 Tang J, Zhang Q, Zeng C et al. Applied Physics A[J], 2013, 111(1): 1099

36 Maiti N, Thomas S, Jacob J A et al. J Colloid Interface Sci[J], $2012,380(1): 141$

\section{陈化胶体金的简便合成与光谱特性}

汤俊琪，欧全宏，符雪文，汪雅琴，林志文，满石清

(云南师范大学, 云南 昆明 650500)

摘 要: 描述了通过只添加氢氧化钠到氯金酸和十六烷基三甲基溴化铵混合液中合成陈化纳米金胶体，并研究了该胶体的光谱特性。基 于傅里叶红外光谱对纳米金的形成机理进行了分析并以紫外可见光谱和扫描电子显微镜表征了添加不同量的氢氧化钠而获得的陈化 $3 \mathrm{~m}$ 的胶体金。同时获得了吸附于陈化了 $3 \mathrm{~m}$ 的胶体金表面上的亚甲基蓝的表面增强拉曼光谱。结果表明，陈化 $3 \mathrm{~m}$ 的胶体金其紫外可见光谱 具有宽的等离子吸收峰，对这种宽化改变进行了解释分析。其透射电子显微镜分析表明在纳米金合成阶段，添加不同量的氢氧化钠可影 响纳米金大小，同时不同量的氢氧化钠影响着胶体金的陈化过程并产生出形状依赖的陈化胶体金。表面增强拉曼光谱的增强特性不同证 明了所形成的陈化胶体金的大小/形状依赖特征。因此，我们期望着这种陈化胶体金能够在生化分析领域被得到开发应用。

关键词：纳米金; 胶体; 陈化过程; 表面增强拉曼散射

作者简介: 汤俊琪, 男, 1984 年生, 博士, 讲师, 云南师范大学物理与电子信息学院, 云南 昆明 650500, 电话: 0871-65941177,

E-mail: tjunqi@163.com 